\title{
THE CONTROL OF PLASTID INHERITANCE IN PELARGONIUM. III
}

\author{
R. A. E. TILNEY-BASSETT \\ Department of Genetics, University College of Swansea
}

Received 18.ii.74

\begin{abstract}
SUMmARY
Selfing two heterozygous green plants derived from crosses between the Pelargonium cultivars Dolly Varden and Flower of Spring produced solely green $F_{2}$ progeny in a ratio of 1 homozygote, $\operatorname{Pr}_{1} \operatorname{Pr}_{1}: 1$ heterozygote, $\operatorname{Pr}_{1} \operatorname{Pr}_{2}$ instead of the expected mendelian $3: 1$ or $1: 2: 1$ ratio. The fact that these $F_{2}$ are all green rules out the possibility that the ratio could be biased through loss of white or variegated embryos as was argued in previous experiments; the fact that the mean fertilisation and embryo survival is the same for families of homozygotes and heterozygotes contradicts zygotic selection; and the fact that embryo death is insufficient to swing the ratio from $3: 1$ to $1: 1$ all point to gametophytic selection against the $\operatorname{Pr}_{2}$ allele on the female side. This implies that the conspicuous differences between the segregation patterns from heterozygous females after $\mathrm{G} \times \mathrm{W}$ plastid crosses occurs despite the fact that the female eggs are of uniform genotype $\operatorname{Pr}_{1}$. Hence the differences between the segregation patterns must be determined by the female parent before meiosis when still heterozygous and diploid.
\end{abstract}

\section{INTRODUCTION}

REcent analysis of extranuclear plastid inheritance in Pelargonium has shown that two alternative patterns of segregation, following $\mathrm{G} \times \mathrm{W}$ plastid crosses, are under the control of the female nuclear genotype. The two segregation patterns have been called type $\mathrm{I}(\mathrm{G}>\mathrm{V}>\mathrm{W})$, in which most offspring are green, rather less variegated and a few are white, or occasionally the variegated are more frequent than green, and type II $(\mathrm{G}>\mathrm{V}<\mathrm{W})$, in which green and white offspring are approximately equally frequent and variegated few (Tilney-Bassett, 1973). It is suggested that the two patterns are controlled by alleles of a nuclear gene, named $\operatorname{Pr}_{1}$ and $\mathrm{Pr}_{2}$, with an effect on plastid replication at the time of fertilisation. Females whose offspring segregate as a type I pattern are homozygous $\operatorname{Pr}_{1} \operatorname{Pr}_{1}$ and females whose offspring segregate as a type II pattern are heterozygous $\operatorname{Pr}_{1} \operatorname{Pr}_{2}$. Selfing the heterozygote cv. "Flower of Spring", and backcrossing it with the homozygote cv. "Dolly Varden ", gives unexpected deviations from monohybrid and backcross ratios. There are two hypotheses to explain these observations:

(1) The deviations can be explained by assuming that the $\operatorname{Pr}_{2}$ allele exhibits gametophytic lethality on the female side so that $\mathrm{Pr}_{2}$ haploid cells after female meiosis do not usually develop into functional eggs that become fertilised. This idea comes from the observation of much greater deviations from the expected 1:1 ratios, owing to the deficit of type II plants, when the female is heterozygous in $\operatorname{Pr}_{1} \operatorname{Pr}_{2} \times \operatorname{Pr}_{1} \operatorname{Pr}_{1}$ crosses than when the male is heterozygous (Tilney-Bassett, 1973). Further support is given by the 
analysis of $G \times W$ and $W \times G$ crosses in D. Varden and F. of Spring, which showed that there is no difference in mean fertilisation, and no difference in survival during embryo development up to maturity and germination (Tilney-Bassett, 1970a); hence heterozygous embryos must survive just as well as homozygous ones. New data is presented in this paper for a large number of type I and type II segregations.

(2) An alternative interpretation is that the death after germination of all the white and some variegated seedlings is biasing the mendelian ratios which are based solely on scoring surviving variegated plants. Hence apparent gametophytic lethality of the $\mathrm{Pr}_{2}$ allele on the female side is due in reality to selection against $\operatorname{Pr}_{1} \operatorname{Pr}_{2}$ heterozygous and, following $\operatorname{Pr}_{1} \operatorname{Pr}_{2} \times$ $\operatorname{Pr}_{1} \operatorname{Pr}_{2}$ crosses, $\operatorname{Pr}_{2} \operatorname{Pr}_{2}$ homozygous offspring. This is not difficult to imagine as about half the offspring from a heterozygous green female parent are variegated or white. It is only necessary to postulate a mechanism by which half the heterozygous and all the homozygous $\operatorname{Pr}_{2} \operatorname{Pr}_{2}$ offspring are closely associated with dying seedlings. My proposal for a mechanism to account for this association is to suggest that the $\operatorname{Pr}_{1}$ allele favours replication of green plastids, and when all the eggs have this genotype a type I pattern results, whereas the $\mathrm{Pr}_{2}$ allele favours the replication of white plastids, and when about half the eggs have the $\operatorname{Pr}_{1}$ genotype and half the $\operatorname{Pr}_{2}$ genotype a type II pattern results. In this manner most heterozygous offspring with the $\operatorname{Pr}_{2}$ allele derived from a $\operatorname{Pr}_{2}$ egg would be white as would homozygous $\operatorname{Pr}_{2} \operatorname{Pr}_{2}$ progeny, and these then die.

One way of testing, whether or not the $\mathrm{Pr}_{2}$ allele is lethal on the female side, is to inbreed pure green heterozygotes and analyse the $F_{2}$ generation of pure green offspring so that there are no mutant white plastids to interact in any way whatsoever with the nuclear genotype. Moreover, in this way, an unbiased sample from the whole of the $\mathbf{F}_{2}$ offspring is tested, instead of one biased by the problem of untested white embryos.

\section{MAterials AND METHODS}

The two parental cultivars used in these experiments were the green (G) and white-over-green (W) clones of Flower of Spring (FS) and Dolly Varden (DV) described in an earlier report, where the methods of pollination and of scoring embryos were also explained (Tilney-Bassett, 1970a). The crossing programme for the inbreds and hybrids from which fertility data are presented, and the methods of estimating the percentage green plastid contribution, were described in a more recent report (Tilney-Bassett, 1973); further fertility data are taken from crosses described in the present paper.

The crossing programme commenced with the choice of two $F_{1}$ hybrids derived from crosses between D. Varden and F. of Spring. These began as variegated seedlings but developed green shoots. The two plants, numbered DV $\mathrm{W} \times \mathrm{G} F \mathrm{~F} / 28$ and $\mathrm{DV} \mathrm{W} \times \mathrm{GFS} / 37$, have been shown to produce a type II segregation in $G \times W$ crosses with white-over-green $F$. of Spring (Tilney-Bassett, 1973; table 5). On the basis of this segregation behaviour they were assumed to be heterozygotes; the present results confirmed this assumption. They were chosen from among many other possible $F_{1}$ hybrids because of their vigour and fertility. The two green $F_{1}$ plants were each selfed and a number of seeds were set, germinated and grown 
up into green $F_{2}$ plants; as expected, there were no variegated or white $\mathrm{F}_{2}$ seedlings. On flowering, about one year after germination, the green $F_{2}$ plants were used as female parents in $G \times W$ crosses with the whiteover-green F. of Spring as the source of mutant plastids. The resulting embryos were scored, 3 weeks after pollination, as green, variegated or white in order to determine the nature of the segregation pattern produced from each green $F_{2}$ plant, and hence the genotype of the green $F_{2}$ plants. In the tables each separate $F_{2}$ plant is identified by one or two letters; the

TABLE 1

Comparison of the mean fertilisation of total and mean survival of mature embryos for families with type $I$ or type II segregation derived from selfs or crosses within and between cultivars Dolly Varden and Flower of Spring Inbreds:

\begin{tabular}{|c|c|c|c|c|c|c|c|}
\hline Selfs and crosses & $\begin{array}{l}\text { Segregation } \\
\text { type }\end{array}$ & $\begin{array}{l}\text { Number of } \\
\text { families }\end{array}$ & $\begin{array}{l}\text { Number of } \\
\text { flowers }\end{array}$ & $\begin{array}{l}\text { Total } \\
\text { embryos }\end{array}$ & $\begin{array}{l}\text { Mean } \\
\text { ertilisation }\end{array}$ & $\begin{array}{l}\text { Mature } \\
\text { embryos }\end{array}$ & $\begin{array}{l}\text { Mean } \\
\text { survival }\end{array}$ \\
\hline \multirow{2}{*}{\multicolumn{8}{|c|}{$\begin{array}{l}\text { Inbreds: } \\
(\mathrm{DV} \mathrm{W} \times \mathrm{G} \mathrm{DV}) \mathrm{G} \times \mathrm{W} \mathrm{DV}\end{array}$}} \\
\hline & I & 7 & 415 & 1385 & 3.337 & 1163 & $2 \cdot 802$ \\
\hline & II & None & & & & & \\
\hline \multirow[t]{2}{*}{$(\mathrm{DV} G \times \mathrm{W} D V) \mathrm{G} \times \mathrm{W} \mathrm{DV}$} & I & 10 & 717 & 2151 & $3 \cdot 000$ & 1932 & $2 \cdot 695$ \\
\hline & II & None & & & & & \\
\hline \multirow[t]{2}{*}{$(F S W \times G F S) G \times W F S$} & I & 14 & 479 & 1351 & $2 \cdot 820$ & 1100 & $2 \cdot 296$ \\
\hline & II & 11 & 309 & 884 & $2 \cdot 861$ & 723 & $2 \cdot 340$ \\
\hline \multirow{3}{*}{$\begin{array}{l}\text { Hybrids: } \\
(\text { FS G } \times \text { W DV) G } \times \text { W FS }\end{array}$} & & & & & & & \\
\hline & I & 12 & 720 & 2869 & 3.985 & 2533 & 3.518 \\
\hline & II & 1 & 31 & 116 & $3 \cdot 7$ & 111 & 3.581 \\
\hline \multirow{2}{*}{$(\mathrm{FS} \mathrm{W} \times \mathrm{G} \mathrm{DV}) \mathrm{G} \times \mathrm{W} \mathrm{DV}$} & I & 12 & 702 & 2383 & $3 \cdot 395$ & 2052 & $2 \cdot 923$ \\
\hline & II & None & & & & & \\
\hline \multirow[t]{2}{*}{$(\mathrm{DV} G \times W \mathrm{WS}) \mathrm{G} \times \mathrm{W} \mathrm{DV}$} & I & 9 & 680 & 204 & $3 \cdot 009$ & 1915 & $2 \cdot 816$ \\
\hline & II & 3 & 279 & 942 & $3 \cdot 376$ & 819 & $2 \cdot 93$ \\
\hline \multirow[t]{2}{*}{$(\mathrm{DV} W \times \mathrm{G} \mathrm{FS}) \mathrm{G} \times \mathrm{W} F \mathrm{FS}$} & I & 20 & 1108 & 4152 & 3.747 & 3610 & $3 \cdot 258$ \\
\hline & II & 15 & 626 & 2185 & $3 \cdot 490$ & 1888 & 3.016 \\
\hline
\end{tabular}

Selfed Hybrids:

$(\mathrm{DV} W \times \mathrm{G} \mathrm{FS} / 28) \mathrm{G}$ self

$\rightarrow \mathrm{G} \mathrm{F}_{\mathbf{2}} \times \mathrm{W}$ FS

$(\mathrm{DV} W \times \mathrm{G}$ FS/37)G self $\rightarrow$ G $F_{2} \times W$ FS

$\begin{array}{rrrrrrr}\text { I } & 13 & 201 & 4616 & 3.065 & 559 & 2 \cdot 781 \\ \text { II } & 14 & 235 & 833 & 3.545 & 735 & 3.128 \\ \text { I } & 9 & 154 & 471 & 3.058 & 411 & 2 \cdot 669 \\ \text { II } & 5 & 92 & 327 & 3.554 & 300 & 3 \cdot 261 \\ & & & & & & \\ & & & & & & \\ \text { I } & 106 & 5176 & 17424 & 3.366 & 15275 & 2 \cdot 951 \\ \text { II } & 49 & 1572 & 5287 & 3.363 & 4576 & 2 \cdot 911\end{array}$

Grand Totals:

absence of certain letters from the alphabet is caused by plants that failed to flower after 1 year, or produced too few flowers to obtain an adequate score.

\section{Fertility OF homozygous aND Heterozygous PLANTS}

In $\mathrm{G} \times \mathrm{W}$ plastid crosses the green clone of $\mathrm{D}$. Varden produces a type I pattern, and that of $F$. of Spring a type II pattern, yet analysis of fertility data showed no difference between the two cultivars (Tilney-Bassett, $1970 a, b)$. It is therefore interesting to compare the fertility of other plants producing a type I or type II pattern. Data from inbreds, hybrids and selfed hybrids are given in table 1 for total embryos fertilised, and for 
surviving embryos when fully expanded 3 weeks after pollination. Individual families derived from the same cross are grouped together. In six cases it is possible to compare the fertilisation and survival means of type I and type II families derived from the same cross, in four of these the type II group shows the slightly higher fertilisation and in two the type I group. After adding the three crosses of the type I group, for which there are no type II families, means for the grand total of all type I and type II fertilities can be determined. As the table shows, these means are extremely similar and are clearly in agreement with the finding for F. of Spring and D. Varden. Hence there is no evidence of any differences in mean fertilisation or embryo survival of progeny derived from homozygous and heterozygous mothers. The 10 to 15 per cent of dead embryos include many green and variegated as well as white ones from heterozygous parents, while from homozygous parents they are mostly green in agreement with the majority of green offspring.

\section{EMbryo SEgRegation}

Solely green $\mathrm{F}_{2}$ seedlings were obtained by selfing two heterozygous green plants derived from crosses between D. Varden and F. of Spring. The green $\mathrm{F}_{2}$ plants were brought to flower and then crossed as females with pollen from the variegated clone of $F$. of Spring. The type I segregation for the progeny of some plants indicates that these $F_{2}$ parents are homozygous $\operatorname{Pr}_{1} \operatorname{Pr}_{1}$, while the type II segregation for the progeny of other plants indicates that these $F_{2}$ parents are heterozygous $\operatorname{Pr}_{1} \operatorname{Pr}_{2}$. The results are shown in tables 2 and 3 . There are 12 type $I$ and 13 type II $F_{2}$ plants derived from selfing DV W $\times$ G FS/28, and eight type I and five type II $\mathrm{F}_{2}$ plants derived from selfing DV W $\times \mathrm{G} \mathrm{FS} / 37$; their combined segregation is 20 type $I$ and 18 type II in close agreement with a $1: 1$ ratio. The type I segregations are remarkable for their very low frequencies of variegated and complete absences of white embryos. The type II segregations are more variable with quite large differences between the lowest and highest frequencies of white embryos, nevertheless these appear to be normally distributed and there is no segregation with a particularly high white phenotype, such as might be expected from a parent homozygous $\operatorname{Pr}_{2} \operatorname{Pr}_{2}$.

Both $F_{1}$ plants were heterozygous for red flower colour and the $F_{2} s$ segregated into red and rose flowered plants. Both red type I and II, and rose type $\mathrm{I}$ and II $\mathrm{F}_{2}$ plants were observed.

\section{Discussion}

The fertility analysis shows that heterozygous plants are just as fertile as homozygous ones, and that embryos of segregating families are no less viable than embryos of true breeding families. It is therefore improbable that there is a strong selection against heterozygous plants between fertilisation and germination, or indeed during their growth to flowering. In other words, there is no reason to think that the ratio of homozygous to heterozygous seedlings grown up into green $F_{2}$ plants is any different from the ratio of homozygous to heterozygous zygotes immediately after fertilisation. Zygotic selection is therefore not the mechanism to account for the observed 1 homozygous : 1 heterozygous $F_{2}$ ratio, following the inbreeding of heterozygous plants, when a monohybrid $1: 2: 1$ or $3: 1$ ratio is to be expected. 
TABLe 2

Tests of green $F_{2}$ plants derived from selfing the green $F_{1}$ between white $D$. Varden and green $F$. of Spring $(D V W \times G F S / 28)$

( $F_{2}$ green plants female by white $F$. of Spring male)

Sibs arranged in order of percentage green plastid contribution

$\mathrm{F}_{2}: \mathrm{A} \quad \mathrm{G} \times \mathrm{W}$ FS

$F_{2}: I \quad G \times W F S$

$F_{2}: L \quad G \times W F S$

$F_{2}: Q \quad G \times W F S$

$\mathrm{F}_{2}: \mathrm{Z} \quad \mathrm{G} \times \mathrm{WFS}$

$F_{2}: A B \quad G \times W F S$

$F_{2}: A C \quad G \times W F S$

$\mathrm{F}_{2}: \mathrm{AE} \quad \mathrm{G} \times \mathrm{W} F \mathrm{~S}$

$\mathrm{F}_{2}: \mathrm{AA} \quad \mathrm{G} \times \mathrm{WFS}$

$\mathrm{F}_{2}: \mathrm{S} \quad \mathrm{G} \times \mathrm{W}$ FS

$F_{2}: Y \quad G \times W F S$

$\mathrm{F}_{2}: \mathrm{K} \quad \mathrm{G} \times \mathrm{WFS}$

$\mathrm{F}_{2}: \mathrm{R} \quad \mathrm{G} \times \mathrm{WFS}$

$F_{2}: C \quad G \times W F S$

$F_{2}: T \quad G \times W F S$

$F_{2}: U \quad G \times W F S$

$F_{2}: X \quad G \times W F S$

$\mathrm{F}_{2}: \mathrm{P} \quad \mathrm{G} \times \mathrm{WFS}$

$\mathrm{F}_{2}: \mathrm{G} \quad \mathrm{G} \times \mathrm{WFS}$

$F_{2}: V \quad G \times W F S$

$F_{2}: J \quad G \times W F S$

$\mathbf{F}_{2}: \mathbf{M} \quad \mathrm{G} \times \mathrm{WFS}$

$\mathrm{F}_{2}: \mathrm{B} \quad \mathrm{G} \times \mathrm{W}$ FS

$\mathrm{F}_{2}: \mathrm{O} \quad \mathrm{G} \times \mathrm{W}$ FS

$F_{2}: A D \quad G \times W F S$
Percentage Embryos

\begin{tabular}{|c|c|c|c|c|c|}
\hline & & & & & \\
\hline $\mathrm{G}$ & V & W & Total & plastids & type \\
\hline $100 \cdot 0$ & - & - & 46 & $100 \cdot 0$ & I \\
\hline $100 \cdot 0$ & - & - & 70 & $100 \cdot 0$ & I \\
\hline $100 \cdot 0$ & - & - & 24 & $100 \cdot 0$ & I \\
\hline $100 \cdot 0$ & 一 & - & 39 & $100 \cdot 0$ & I \\
\hline $100 \cdot 0$ & 一 & - & 45 & $100 \cdot 0$ & I \\
\hline $100 \cdot 0$ & - & - & 91 & $100 \cdot 0$ & I \\
\hline $100 \cdot 0$ & - & - & 38 & $100 \cdot 0$ & I \\
\hline $100 \cdot 0$ & - & - & 31 & $100 \cdot 0$ & I \\
\hline $98 \cdot 2$ & $1 \cdot 8$ & - & 56 & $99 \cdot 8$ & I \\
\hline $97 \cdot 2$ & $2 \cdot 8$ & - & 72 & $99 \cdot 8$ & I \\
\hline $96 \cdot 4$ & 3.6 & - & 28 & $99 \cdot 7$ & I \\
\hline $96 \cdot 8$ & $3 \cdot 2$ & - & 63 & $99 \cdot 1$ & I \\
\hline $71 \cdot 4$ & - & $28 \cdot 6$ & 35 & $71 \cdot 4$ & II \\
\hline $69 \cdot 6$ & - & $30 \cdot 4$ & 23 & $69 \cdot 6$ & II \\
\hline $58 \cdot 9$ & $9 \cdot 6$ & $31 \cdot 5$ & 73 & $65 \cdot 9$ & II \\
\hline $60 \cdot 4$ & $1 \cdot 0$ & $38 \cdot 6$ & 96 & $61 \cdot 1$ & II \\
\hline $57 \cdot 6$ & $3 \cdot 0$ & $39 \cdot 4$ & 66 & $60 \cdot 2$ & II \\
\hline $55 \cdot 3$ & $2 \cdot 7$ & $42 \cdot 0$ & 112 & $56 \cdot 9$ & II \\
\hline $53 \cdot 8$ & $2 \cdot 1$ & $44 \cdot 1$ & 93 & $55 \cdot 7$ & II \\
\hline $54 \cdot 8$ & $2 \cdot 4$ & $42 \cdot 8$ & 42 & $55 \cdot 2$ & II \\
\hline 53.5 & $1 \cdot 7$ & $44 \cdot 8$ & 58 & $54 \cdot 3$ & II \\
\hline $51 \cdot 3$ & $2 \cdot 6$ & $46 \cdot 1$ & 76 & $53 \cdot 2$ & II \\
\hline $52 \cdot 0$ & - & $48 \cdot 0$ & 25 & $52 \cdot 0$ & II \\
\hline $51 \cdot 9$ & - & $48 \cdot 1$ & 81 & $51 \cdot 9$ & II \\
\hline $44 \cdot 8$ & $3 \cdot 5$ & $51 \cdot 7$ & 29 & $48 \cdot 3$ & II \\
\hline
\end{tabular}

TABle 3

Tests of green $F_{2}$ plants derived from selfing the green $F_{1}$ between white $D$. Varden and green $F$. of Spring $(D V W \times G F S / 37)$

( $F_{2}$ green plants female by white $F$. of Spring male)

Sibs arranged in order

of percentage green

plastid contribution

$\mathrm{F}_{2}: \mathrm{A} \quad \mathrm{G} \times \mathrm{W} \mathrm{FS}$

$\mathrm{F}_{2}: \mathrm{H} \quad \mathrm{G} \times \mathrm{W}$ FS

$F_{2}: I \quad G \times W F S$

$\mathrm{F}_{2}: \mathrm{J} \quad \mathrm{G} \times \mathrm{W}$ FS

$\mathrm{F}_{2}: \mathrm{L} \quad \mathrm{G} \times \mathrm{WFS}$

$F_{2}: E \quad G \times W F S$

$F_{2}: C \quad G \times W F S$

$\mathrm{F}_{2}: \mathrm{N} \quad \mathrm{G} \times \mathrm{WFS}$

$\mathrm{F}_{2}: \mathrm{D} \quad \mathrm{G} \times \mathrm{WFS}$

$F_{2}: G \quad G \times W F S$

$\mathrm{F}_{2}: \mathrm{O} \quad \mathrm{G} \times \mathrm{WFS}$

$\mathrm{F}_{2}: \mathrm{F} \quad \mathrm{G} \times \mathrm{WFS}$

$\mathrm{F}_{2}: \mathrm{M} \quad \mathrm{G} \times \mathrm{WFS}$

$33 / 3-\mathrm{Z}$
Percentage embryos

$\begin{array}{rccc}\overbrace{\mathrm{G}} & \mathrm{V} & \mathrm{W} & \text { Tota } \\ 100 \cdot 0 & - & - & 38 \\ 100 \cdot 0 & - & - & 84 \\ 100 \cdot 0 & - & - & 34 \\ 100 \cdot 0 & - & - & 55 \\ 100 \cdot 0 & - & - & 95 \\ 98 \cdot 3 & 1 \cdot 7 & - & 58 \\ 96.5 & 3.5 & - & 58 \\ 96.7 & 3.3 & - & 30 \\ 62.5 & 13.6 & 23.9 & 88 \\ 68.6 & - & 31.4 & 35 \\ 65.6 & - & 34.4 & 32 \\ 58.5 & 4.3 & 37.2 & 94 \\ 54.8 & 2.7 & 42.5 & 73\end{array}$

Percentage Segregation green pattern

plastids type

$100 \cdot 0$

$100 \cdot 0$

$100 \cdot 0$

$100 \cdot 0$

$100 \cdot 0$

$99 \cdot 9$

$99 \cdot 6$

$99 \cdot 2$

$70 \cdot 1$

$68 \cdot 6$

$65 \cdot 6$

$61 \cdot 0$

$56 \cdot 3$
I

I

I

I

I

I

II

II

II

II 
Moreover, in order for zygotic elimination of all homozygous $\left(\operatorname{Pr}_{2} \operatorname{Pr}_{2}\right)$ and half the heterozygous $\left(\operatorname{Pr}_{1} \operatorname{Pr}_{2}\right)$ embryos to change the ratio from $3: 1$ to $1: 1$, there would have to be an elimination of 50 per cent of the embryos, whereas the observed death between fertilisation and germination in type II plants is usually not more than 30 per cent and often considerably less. The present ratio of 1 type I : 1 type II $F_{2}$ plants confirms that obtained by selfing F. of Spring (Tilney-Bassett, 1973) yet, on this occasion, the $F_{1}$ selfing programme has kept out all mutant plastids so that one cannot explain away the unexpected $1: 1$ ratio on the basis of the loss of heterozygous embryos through association with the death of white embryos. The weight of evidence therefore points overwhelmingly to gametophytic lethality of the $\operatorname{Pr}_{2}$ allele on the female side, which would give a ratio of $1 \operatorname{Pr}_{1} \operatorname{Pr}_{1}: 1 \operatorname{Pr}_{1} \operatorname{Pr}_{2}$ corresponding to the observed segregation pattern. It is presumed that lethality is less important on the male side as found previously (see Introduction).

Agreement with the first hypothesis outlined in the introduction does not entirely rule out the second hypothesis as we still need to account for the differences between type I and type II patterns. The alternative patterns are now seen to be all the more remarkable because in a type I segregation all the eggs are identical $\operatorname{Pr}_{1}$ because the parent is homozygous $\operatorname{Pr}_{1} \operatorname{Pr}_{1}$, and in a type II segregation all the eggs are identical $\operatorname{Pr}_{1}$ because, although the parent is heterozygous $\operatorname{Pr}_{1} \mathrm{Pr}_{2}$, the $\operatorname{Pr}_{2}$ gametophytes do not, or very rarely, produce any $\operatorname{Pr}_{2}$ eggs. It has already been shown very clearly that the main control of the segregation pattern is dependent on the nuclear genotype of the female parent. I first suggested that this was because the female produced the eggs and from the heterozygous female half the eggs would be $\operatorname{Pr}_{1}$, and would encourage the replication of green plastids, and half would be $\mathrm{Pr}_{2}$ and would encourage the replication of white plastids (Tilney-Bassett, 1973). But if, as now seems to be the case, the $\mathrm{Pr}_{2}$ gametophytes seldom produce viable eggs, then the very conspicuous differences between a type $\mathrm{I}(\mathrm{G}>\mathrm{V}>\mathrm{W})$ and a type II $(\mathrm{G}>\mathrm{V}<\mathrm{W})$ segregation pattern must occur despite the fact that the female eggs are of uniform genotype $\operatorname{Pr}_{1}$. This means, at least in the two families studied, that the differences between the $\operatorname{Pr}_{1}$ eggs that decide whether it is the white or the green plastids that replicate in the zygote are pre-determined by the female before meiosis when still heterozygous and diploid. How this control operates is still unknown but comparison with another system is not irrelevant.

Sager and Ramanis (1973) have recently proposed a model for the control of maternal inheritance in Chlamydomonas. In their model, the female $(\mathrm{mt}+)$ parent contributes three essential components of the system: (1) a modification enzyme responsible for the observed density shift of female chloroplast DNA, (2) a regulator substance which activates the modification enzyme after zygote formation, and (3) a second regulator substance which activates a restriction enzyme produced in the male $(\mathrm{mt}-)$ parent. The restriction enzyme responsible for degrading male chloroplast DNA is postulated to be synthesised in the male gamete, but activated by a regulator from the female parent some time after mating. In the absence of any biochemical investigations, it is difficult to discuss a model for Pelargonium in such detail, but it is very doubtful if the two systems could be exactly the same. In Chlamydomonas the two isogametes fuse at fertilisation, and each contains a chloroplast, so that the zygote always begins with one chloroplast from 
each parent, yet the male chloroplast DNA is normally inactivated with high efficiency (Sager, 1972). In Pelargonium, plastid transmission by the male is successful in $\mathrm{G} \times \mathrm{W}$ as well as $\mathrm{W} \times \mathrm{G}$ crosses so that there is probably no mechanism aimed at preventing male transmission. On the other hand, after most crosses with homozygous D. Varden, green plastids are more effectively transmitted than white, whichever way the cross is made (TilneyBassett, 1970b). Hence in Pelargonium we should probably be looking for a mechanism that seeks to recognise and remove abnormal plastids and plastid DNA irrespective of the parental source. Observation of a considerable number of type I segregating families derived from the crossing programme shows that the success with which mutant white plastids are removed varies from poor, with up to 40 per cent white plastid contribution, to highly efficient, with no white plastid contribution. A similar picture emerged from a study of 15 other green cultivars tested for their segregation pattern (Tilney-Bassett, 1974). This study also demonstrated the commonness of the homozygote and the rarity of the heterozygote, suggesting that the $\operatorname{Pr}_{1}$ is the wild type and the semi-lethal $\operatorname{Pr}_{2}$ the mutant allele.

The high proportion of white embryos in the offspring of heterozygous plants could be interpreted as a breakdown in the recognition system and is perhaps indicative of the inability of the $\operatorname{Pr}_{2}$ allele to produce an essential component of this system. It is, however, to be expected that the heterozygote would produce the missing component from the $\mathrm{Pr}_{1}$ allele, so how do the $\operatorname{Pr}_{1}$ eggs come to differ? One possibility is that the informational molecules produced by the heterozygote to control plastid replication in the zygote are not produced in sufficient quantity from only one functional allele so that there is a segregation or dilution during the formation of the eggs. An alternative possibility would be for the heterozygote to behave as a functional mosaic so that some lineages become effectively $\operatorname{Pr}_{1}$ in phenotype, and others effectively $\operatorname{Pr}_{2}$, and the $\operatorname{Pr}_{1}$ eggs would receive the information dependent upon which allele was functional in the heterozygote prior to meiosis. The latter alternative more readily accounts for the remarkable switch that can allow the formation of either green or white embryos in approximately equal frequency with very few variegated. It might be tested by looking for significant heterogeneity of segregation within flowers, providing the switch in control occurred sufficiently early.

Another facet of the problem is the timing of the loss of the $\operatorname{Pr}_{2}$ gametophytes. Hints as to what might be the mechanism for this loss can be gained from an examination of flower structure and fertilisation data. Examination of serial sections of whole ovaries 5 days after pollination revealed that on average more than half the ovules per flower were shrivelled. These were so distorted in shape, modified in cell structure and reduced in size that no embryo sac could be seen and I assumed they could not have been fertilised (Tilney-Bassett, 1965). After more detailed observations with cv. "Purple Heart", Tsai, Harney and Peterson (1973) showed that these ovules started with an apparently normal embryo sac at the time of pollination, which then rapidly collapsed through not being fertilised. Hence in Purple Heart, and perhaps F. of Spring and D. Varden, it is a failure of fertilisation that gives rise to the shrivelled ovules rather than failure to form a normal embryo sac. This being so, there are ten potentially functional ovules per flower of which only three to four are fertilised on average. This means that if all $\mathrm{Pr}_{2}$ ovules are rejected there still remain 
sufficient $\operatorname{Pr}_{1}$ ovules that could be fertilised to maintain the observed mean fertilisation in type II families, providing there is enough flexibility in their position. In the cultivar "Paul Crampel", which behaves as a type I plant, only 3.5 per cent of the developing ovules were found in the lower position of the two superposed ovules per carpel, whereas in F. of Spring the value was 20.6 per cent (Tilney-Bassett, 1963). This suggests that there is a preference for upper ovules, but that this might be at least partly overcome by a preference for $\operatorname{Pr}_{1}$ ovules instead of $\operatorname{Pr}_{2}$, indeed some observed frequencies of $\mathrm{F}$. of Spring flowers with four or five developing embryos are much too high for them to be both all in the upper position and all $\mathrm{Pr}_{1}$; either some of them must be $\operatorname{Pr}_{2}$ or some must be developing in the lower position. Further analysis of the shifts in frequency from upper to lower positions after type I and type II segregations should reveal whether this is indeed the mechanism for sifting out the $\operatorname{Pr}_{1}$ eggs from a mixture of $\operatorname{Pr}_{1}$ and $\operatorname{Pr}_{2}$.

The present studies suggest that the $\operatorname{Pr}_{2}$ allele has two major effects. The first appears to be initiated in the heterozygous female parent before meiosis, although the response is not observed until after fertilisation when the plastids replicate at the start of embryo development. The second effect appears to bring about the lethality of the female gametophyte sometime after meiosis and before fertilisation. Experiments to verify and pinpoint still more accurately the timing of these effects are now in progress.

\section{REFERENCES}

SAger, R. 1972. Cytoplasmic Genes and Organelles. Academic Press, New York and London. SAGER, R., AND RAMANIs, z. 1973. The mechanism of maternal inheritance in Chlamydomonas: biochemical and genetic studies. Theoretical and Applied Genetics, 43, 101-108. TILNEY-BASSETT, R. A. E. 1963. Genetics and plastid physiology in Pelargonium. Heredity, 18, 485-504.

TILNEY-BASSETT, R. A. E. 1965. Genetics and plastid physiology in Pelargonium. II. Heredity, 20, 451-466.

TILNEY-BASSETT, R. A. E. 1970a. Genetics and plastid physiology in Pelargonium. III. Effect of cultivar and plastids on fertilisation and embryo survival. Heredity, 25, 89-103.

TILNEY-BASSET, R. A. E. $1970 b$. The control of plastid inheritance in Pelargonium. Genet. Res., Camb., 16, 49-61.

TILNEY-BASSETT, R. A. E. 1973. The control of plastid inheritance in Pelargonium. II. Heredity, 30, 1-13.

TILNEY-BASSETT, R. A. E. 1974. Unpublished results.

TSAI, A. H., HARNEY, P. M., AND PETERSON, R. L. 1973. Megasporogenesis and megagametogenesis in Pelargonium $\times$ hortorum. Can. 7. Bot., 51, 607-612. 